\title{
Genetic diversity in Italian Lactobacillus sanfranciscensis strains assessed by multilocus sequence typing and pulsed-field gel electrophoresis analyses
}

\author{
Claudia Picozzi, Gaia Bonacina, lleana Vigentini and Roberto Foschino
}

Correspondence

Roberto Foschino

roberto.foschino@unimi.it

Received 21 December 2009

Revised 4 March 2010

Accepted 29 March 2010
Dipartimento di Scienze e Tecnologie Alimentari e Microbiologiche, Università degli Studi di Milano, via Celoria 2, 20133 Milano, Italy

Lactobacillus sanfranciscensis is a lactic acid bacterium that characterizes the sourdough environment. The genetic differences of 24 strains isolated in different years from sourdoughs, mostly collected in Italy, were examined and compared by PFGE and multilocus sequence typing (MLST). The MLST scheme, based on the analysis of six housekeeping genes ( $g d h, g y r A, \operatorname{map} A$, nox, pgmA and pta) was developed for this study. PFGE with the restriction enzyme Apal proved to have higher discriminatory power, since it revealed 22 different pulsotypes, while 19 sequence types were recognized through MLST analysis. Notably, restriction profiles generated from three isolates collected from the same firm but in three consecutive years clustered in a single pulsotype and showed the same sequence type, emphasizing the fact that the main factors affecting the dominance of a strain are correlated with processing conditions and the manufacturing environment rather than the geographical area. All results indicated a limited recombination among genes and the presence of a clonal population in L. sanfranciscensis. The MLST scheme proposed in this work can be considered a useful tool for characterization of isolates and for indepth examination of the strain diversity and evolution of this species.

\section{INTRODUCTION}

Sourdough technology is widespread in Europe, and is traditionally used in bread making for a variety of baked products, such as rye and wheat bread, crackers, brioches, Italian panettone and similar cakes, some pizzas and numerous local baked goods (De Vuyst \& Neysens, 2005). The type of cereal, recipe formulation, starter method (backslopping or use of selected cultures), dough yield, redox potential, fermentation time and temperature are the environmental factors that affect the dominant microbiota, which is mainly constituted of lactic acid bacteria and yeasts (Vogel et al., 1996, 1999; De Vuyst et al., 2009). In particular, the metabolic activities of heterofermentative lactobacilli involved in most sourdough production provide beneficial effects on flavour (Thiele et al., 2002; Hansen \& Schieberle, 2005), nutritional properties (Liljeberg et al., 1995; Liljeberg \& Björck, 1996; Di Cagno et al., 2002, 2004), texture

Abbreviations: MLST, multilocus sequence typing; ST, sequence type; UPGMA, unweighted pair group method with arithmetic means.

The GenBank/EMBL/DDBJ accession numbers for the gdh, gyrA, mapA, nox, pgmA and pta sequences of the Lactobacillus sanfranciscensis strains analysed in this study are GU454588-GU454611, GU454612-GU454635, GU454636-GU454659, GU454660GU454683, GU454684-GU454707 and GU454708-GU454731, respectively.
(Korakli et al. 2001; Tieking \& Gänzle, 2005; Arendt et al., 2007) and shelf-life of the end products (Corsetti et al., 1998a; Schnürer \& Magnusson, 2005).

Lactobacillus sanfranciscensis is considered a key microorganism (Gobbetti et al., 1996), being the predominant bacterial species in type I sourdoughs for San Francisco bread and many traditional Italian and German baked products (Corsetti et al., 2001; Foschino et al., 2001; Meroth et al., 2003). The increasing knowledge of sourdough ecology is leading to the improvement of the quality of the end product through the use of starter cultures with enhanced technological capabilities, such as exopolysaccharide production (Korakli et al., 2003; Lacaze et al., 2007), antifungal activity (Corsetti et al., 1998b; Schnürer \& Magnusson, 2005), antistaling properties (Corsetti et al., 2000; Moore et al., 2007) and decreased gluten intolerance (Di Cagno et al., 2005; Gobbetti et al., 2007). The identification of $L$. sanfranciscensis at strain level proves to be crucial as a consequence of the rising interest in the above-mentioned strain-related functional traits and for monitoring patented technologies in sourdough production. Moreover, the accurate detection of a bacterial strain could be a valuable criterion for traceability systems, in order to support the typicality of the traditional fermented foods by providing information for consumers and safeguarding the autochthonous microbiota. In fact, the possibility of extracting 
amplifiable microbial DNA directly from panettone cake after heat treatment, and consequently of identifying the species involved in the fermentative process, has recently been demonstrated (Picozzi et al., 2006).

Genetic characterization at the strain level has already been evaluated using different techniques (Zapparoli et al., 1998; Randazzo et al., 2005; Catzeddu et al., 2006; Corsetti et al., 2007; De Angelis et al., 2007; Valcheva et al., 2007). Although random amplified polymorphic DNA (RAPD)PCR assays have been presented as a suitable tool to detect genetic polymorphism within a species, it is often difficult to compare the results from different studies, since they are heavily dependent on the experimental operating conditions. At the same time, repetitive element PCR (rep-PCR) has proved to be a simple fingerprinting application with high discriminatory power, but with the same difficulties as RAPD-PCR.

PFGE analysis has been universally recognized as suitable to determine intra-specific diversity, having been shown to be the most appropriate technique for the typing of bacterial isolates (Tenover et al., 1995); nevertheless, it also has some disadvantages, such as high consumable costs, taking a long time to perform, and complexity. Moreover, some strains have been shown to be difficult to handle due to problems with cell wall disruption and in the generation of 'readable' restriction patterns.
Recently, multilocus sequence typing (MLST) has been used as a novel approach for typing non-pathogenic food bacteria, such as Oenococcus oeni (De las Rivas et al., 2004; Bilhère et al., 2009), Lactobacillus casei (Cai et al., 2007; Diancourt et al., 2007) and Lactobacillus plantarum (De las Rivas et al., 2006; Tanganurat et al., 2009), in order to obtain a precise and unambiguous characterization of strains collected from autochthonous microbiota in natural fermentations or used in commercial starter cultures.

The aims of this work were to explore the polymorphisms in nucleotide sequences of six housekeeping genes in $L$. sanfranciscensis, to develop an MLST protocol and to compare its discriminatory power with a PFGE technique for this species.

\section{METHODS}

Bacterial strains and growth conditions. In this study, a total of 24 L. sanfranciscensis strains were examined (Table 1), including strains previously isolated as dominant populations from sourdoughs collected in Italy at different times and places and reference strains obtained from an international collection. One strain was isolated from a Brazilian sourdough sample. Bacteria were grown at $30{ }^{\circ} \mathrm{C}$ for 24-48 h in modified SanFrancisco medium (SFM) broth or agar (Picozzi et al., 2005). Concentrated cultures were stored at $-80{ }^{\circ} \mathrm{C}$ in the same medium with $20 \%(\mathrm{w} / \mathrm{v})$ glycerol.

Table 1. Information on $L$. sanfranciscensis strains isolated from sourdoughs and their allele profiles at each locus

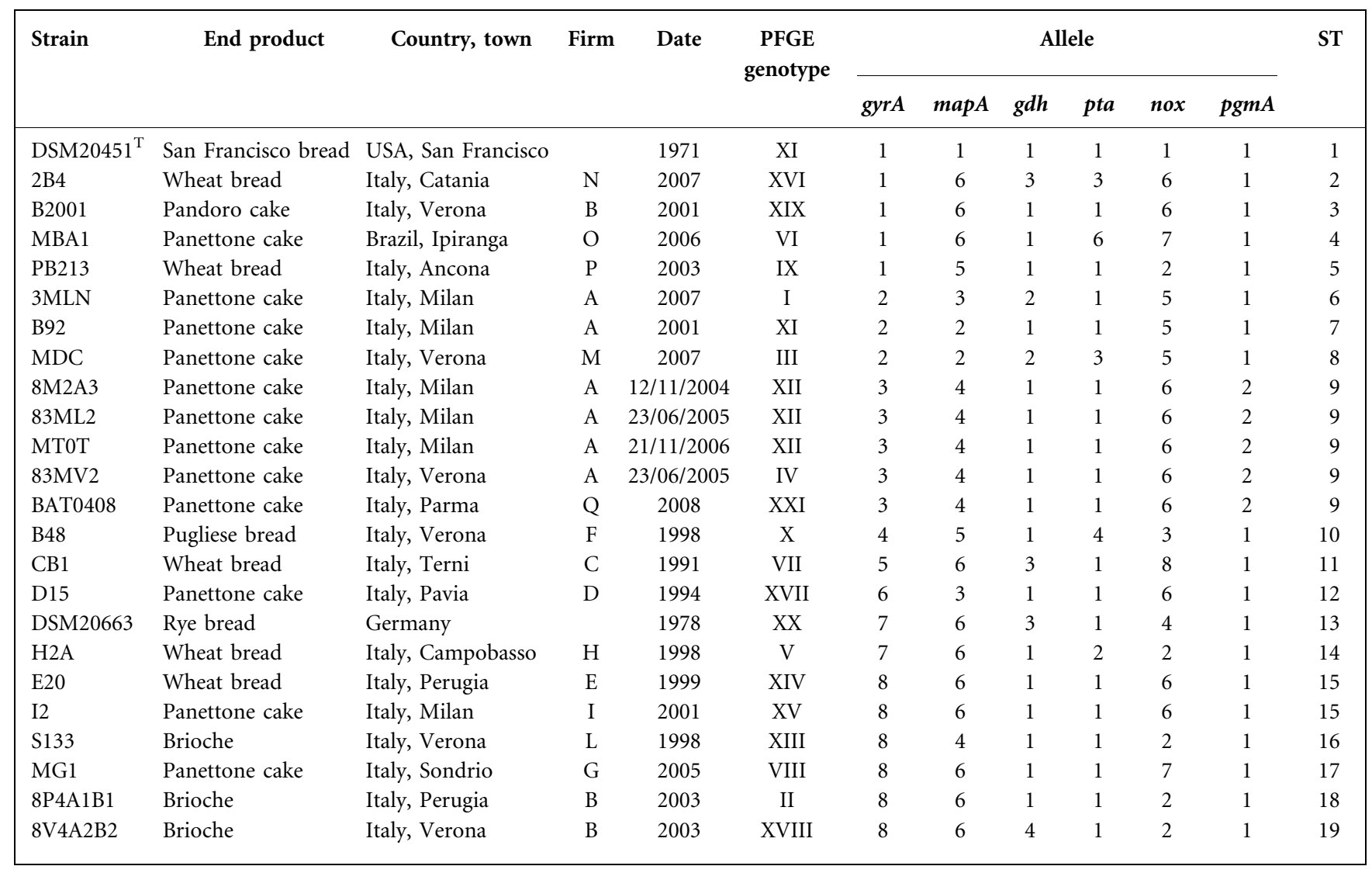


The evaluation of the generation time of an L. sanfranciscensis dominant strain in a 'mother' dough for panettone was carried out at one firm (firm A) according to the existing operating conditions. Approximately $10 \mathrm{~g}$ sample was diluted in $90 \mathrm{ml}$ sterile peptone water and homogenized in a Stomacher 400 Circulator (Seward) for $5 \mathrm{~min}$ at 260 r.p.m. Aliquots of the appropriate dilutions were plated on modified SFM agar and incubated at $30{ }^{\circ} \mathrm{C}$ for $48 \mathrm{~h}$. Microbial counts were replicated in three independent experiments.

Species identification. Bacterial DNA was extracted using an Archive Pure DNA Purification System (5 PRIME) according to the manufacturer's instructions. A preliminary identification was performed through the recognition of the electrophoretic profile generated from the amplification of internal ribosomal spacers according to Valcheva et al. (2007). Furthermore, all the strains were subjected to the sequencing of a portion of the $16 \mathrm{~S}$ rRNA-coding gene in order to confirm that they belonged to the species. The amplification reaction was performed as described by Borgo et al. (2007) using a Biometra thermocycler. The amplification products were purified on QIAquick spin columns (Qiagen) for direct sequencing with the PCR forward primer using a DYEnamic ET Terminator Cycle Sequencing kit (Amersham Pharmacia Biotech), in accordance with the manufacturer's protocol, and an ABI PRISM 310 Genetic Analyzer (Applied Biosystems).

PFGE analysis. DNA samples were prepared according to Zapparoli et al. (1998). Briefly, fresh cell suspensions of $\mathrm{OD}_{600} 1.0$ in SE buffer (75 mM NaCl, $25 \mathrm{mM}$ EDTA, pH 7.7) were mixed with $2 \%(\mathrm{w} / \mathrm{v})$ Certified Molecular Biology Agarose (Bio-Rad) and pipetted into a plug mould. The blocks were treated with lysozyme $\left(3 \mathrm{mg} \mathrm{ml}^{-1}\right)$ at $37^{\circ} \mathrm{C}$ for $12 \mathrm{~h}$, then with $1 \%(\mathrm{w} / \mathrm{v}) \mathrm{N}$-lauryl sarcosine and proteinase $\mathrm{K}(1 \mathrm{mg}$ $\mathrm{ml}^{-1}$ ) at $37^{\circ} \mathrm{C}$ for $16 \mathrm{~h}$. Plugs were washed several times in $1 \times$ TE buffer (Tris/HCl $10 \mathrm{mmol}^{-1}, \mathrm{pH} 8.0$, EDTA $100 \mathrm{mmol}^{-1}$ ) and subjected to overnight DNA digestion at $37{ }^{\circ} \mathrm{C}$ with $10 \mathrm{U}$ ApaI (MBI Fermentas). Plugs were subjected to PFGE on a CHEF-DR II apparatus (Bio-Rad). DNA fragments were separated in $1 \%(\mathrm{w} / \mathrm{v})$ Pulsed Field Certified Agarose (Bio-Rad) in $0.5 \times$ TBE buffer $(45 \mathrm{mM}$ Tris/ $\mathrm{HCl}, 45 \mathrm{mM}$ boric acid, $1 \mathrm{mM}$ EDTA, $\mathrm{pH}$ 8.0). A switch time ranging from 0.5 to $8 \mathrm{~s}$ for $17 \mathrm{~h}$ at a constant voltage of $6.0 \mathrm{~V} \mathrm{~cm}^{-1}$ at $14{ }^{\circ} \mathrm{C}$ was adopted.

The DSM20663 strain was used as an internal reference strain. After migration, gels were stained with ethidium bromide, photographed under UV light, and analysed with a GelDoc XR system (Bio-Rad).

Sequence analysis. The following six loci were chosen for the sequence analysis scheme: $g d h$, encoding glucose-6-phosphate dehy- drogenase (accession no. AJ810804), gyrA, encoding the A subunit of DNA gyrase (AY912125), mapA, encoding maltose phosphorylase (AJ224340), nox, encoding an $\mathrm{NADH}$ oxidase (AB035801), pgmA, encoding a phosphoglucomutase (AJ224340), and pta, encoding phosphotransacetylase (AB035800). These housekeeping genes were selected on the basis of their putative function and on the availability of sequence data for L. sanfranciscensis.

Primers were designed with the online software Primo Pro 3.4 (http:// changbioscience.com/primo/primo.html), using sequences of highly conserved DNA regions of these $L$. sanfranciscensis genes obtained from GenBank (Table 2).

A $25 \mu \mathrm{l}$ reaction mixture for PCR amplification containing $20 \mathrm{ng}$ template DNA, $10 \mathrm{mM}$ Tris/ $\mathrm{HCl}(\mathrm{pH} 8.8), 50 \mathrm{mM} \mathrm{KCl}, 1.5 \mathrm{mM}$ $\mathrm{MgCl}_{2}, 200 \mu \mathrm{M}$ of each deoxynucleoside triphosphate, $1 \mu \mathrm{M}$ of each primer and $1 \mathrm{U}$ Taq polymerase (Expand High Fidelity PCR System, Roche) was prepared. The reaction was performed using a Biometra thermocycler. The temperature profile used the following cycling parameters: $5 \mathrm{~min}$ at $95{ }^{\circ} \mathrm{C}$, followed by 35 cycles of $1 \mathrm{~min}$ at $95{ }^{\circ} \mathrm{C}$, $1 \mathrm{~min}$ at 55,60 or $63{ }^{\circ} \mathrm{C}$ (see Table 2), $1 \mathrm{~min}$ at $72{ }^{\circ} \mathrm{C}$, and $10 \mathrm{~min}$ at $72{ }^{\circ} \mathrm{C}$. Amplified products were resolved on a $1.5 \%(\mathrm{w} / \mathrm{v})$ agarose gel in $1 \times$ TAE ( $40 \mathrm{mM}$ Tris/ $\mathrm{HCl}, \mathrm{pH} 8.2,1 \mathrm{mM}$ EDTA), stained with ethidium bromide and photographed under UV illumination.

The amplification products were purified on QIAquick spin columns (Qiagen) for sequencing with the respective forward and reverse primers (Table 2), by Primm.

The DNA sequences of the L. sanfranciscensis strains analysed have been deposited in GenBank (Table 2).

Data analysis. For the PFGE data, the densitometric values from the electrophoretic bands were transferred to BioNumerics 5.10 software (Applied Maths). The fingerprints obtained were compared by means of the Dice coefficient, and cluster analysis was performed by the unweighted pair group method with arithmetic means (UPGMA).

For the MLST analysis, the sequences obtained for each locus were compared for all isolates, and an allele number was given to each distinct sequence variant. Each isolate was defined by an allele profile or sequence type (ST) derived from the combination of alleles at the six loci analysed (Table 1). The STs were identified by arbitrary numbers assigned in order of description.

Sequence alignments and comparison were done with CLUSTAL_X (http://www.clustal.org/) and converted into MEGA and NEXUS files

Table 2. Primers used for MLST, and accession numbers of sequences of investigated loci

\begin{tabular}{|c|c|c|c|c|c|c|}
\hline Protein & Gene & Primers & Sequence $\left(5^{\prime} \rightarrow 3^{\prime}\right)$ & $\begin{array}{l}\text { PCR product } \\
\text { length }(b p)\end{array}$ & $\begin{array}{c}\text { Annealing } \\
\text { temperature }\left({ }^{\circ} \mathrm{C}\right)\end{array}$ & Accession nos \\
\hline $\begin{array}{l}\text { Glucose-6-phosphate } \\
\text { dehydrogenase }\end{array}$ & $g d h$ & GDH1F & AAGTTATATCCTGCAATCTTT & 489 & 55 & GU454588-GU454611 \\
\hline & & GDH1R & TTACCTAAGTAATGATCAATTC & & & \\
\hline Subunit A of DNA gyrase & gyrA & $\begin{array}{l}\text { GYRA1F } \\
\text { GYRA1R }\end{array}$ & $\begin{array}{l}\text { CGAATATTCCGCCTCACA } \\
\text { GAGCACCTTCAATAATAGCA }\end{array}$ & 484 & 55 & GU454612-GU454635 \\
\hline Maltose phosphorylase & mapA & $\begin{array}{l}\text { MAP2F } \\
\text { MAP2R }\end{array}$ & $\begin{array}{l}\text { ACCCAGACTACTTCGGTAA } \\
\text { GAAGCGAATGCCTTGTTG }\end{array}$ & 735 & 63 & GU454636-GU454659 \\
\hline NADH oxidase & nox & $\begin{array}{l}\text { NOX1F } \\
\text { NOX1R }\end{array}$ & $\begin{array}{l}\text { GTAGGTTGTACTCACGCT } \\
\text { CAGTGTTAGGGCGGAAAC }\end{array}$ & 734 & 55 & GU454660-GU454683 \\
\hline Phosphotransacetylase & pta & $\begin{array}{l}\text { PTA1F } \\
\text { PTA1R }\end{array}$ & $\begin{array}{l}\text { GTTTCAGGTGCTGCTCAC } \\
\text { TGATACTTTATAAACGTCTTC }\end{array}$ & 583 & 55 & GU454708-GU454731 \\
\hline Phosphoglucomutase & $\operatorname{pgmA}$ & $\begin{array}{l}\text { PGM2F } \\
\text { PGM2R }\end{array}$ & $\begin{array}{l}\text { GACTTGGATGGCGTCATC } \\
\text { ATGTAGCGTTGCTGGGTC }\end{array}$ & 409 & 60 & GU454684-GU454707 \\
\hline
\end{tabular}


with START2 (Sequence type Analysis and Recombinatorial Tests; http://www.medawar.ox.ac.uk/maiden/software.shtml). Phylogenetic trees were assembled with MEGA version 4.1 software (http://www. megasoftware.net). Dendrograms were constructed by application of UPGMA. The percentage of bootstrap confidence levels for internal branches, as defined by the MEGA program (Kumar et al., 1994), was calculated from 1000 random resamplings.

To assess the degree of tree-like structure in the alleles found for each locus in the complete set of 24 isolates, the method of split decomposition, performed with SPLITSTREE 4.0, was used (Huson \& Bryant, 2006). The START2 program was used to calculate the ratio of non-synonymous to synonymous substitutions (the $\mathrm{d}_{\mathrm{N}} / \mathrm{d}_{\mathrm{S}}$ ratio; Nei \& Gojobori, 1986) and the Sawyer's run test for intragenic recombination. The measure of linkage equilibrium between alleles at the six housekeeping genes was assessed by calculating the index of association $\left(\mathrm{I}_{\mathrm{A}}\right)$ (Smith et al., 1993). To avoid dependence on the number of loci, the standardized $\mathrm{I}_{\mathrm{A}}\left(\mathrm{I}_{\mathrm{A}}^{\mathrm{S}}\right)$ was also calculated (Haubold \& Hudson, 2000).

\section{RESULTS}

\section{Characterization of $L$. sanfranciscensis strains by PFGE}

A pattern repeatability of $91 \%$ was assessed by determining the similarity percentage joining independent replicates of
L. sanfranciscensis DSM20663 (data not shown), and this value was considered as a threshold to define identical pulsotypes (Tenover et al., 1995; Ravelo et al., 2003).

From 24 L. sanfranciscensis strains considered in this work, 22 pulsotypes (PTI to PTXXII) were obtained (Fig. 1); this outcome was expected, since $L$. sanfranciscensis strains were recovered from different locations, types of sourdough and years. All the strains were clearly subdivided into two clusters, named A and B, composed of 11 and 13 PFGE patterns that shared more than 54 and $55 \%$ similarity, respectively. In general, no relationships among geographical origin, sourdough technology or year of isolation were observed. However, the isolates 8M2A3, 83ML2 and MT0T (cluster B), which were collected from the 'mother' dough from the same firm (A) but in three consecutive years (2004, 2005 and 2006), proved to be closely related (PTXII). On the other hand, B92 and 3MLN strains, still collected from samples from firm A in different years (2001 and 2007, respectively), belonged to different pulsotypes (PTXI and PTI) and were both located in cluster A. Moreover, the restriction profiles generated from 8P4A1B1 (cluster $\mathrm{A}$ ) and 8V4A2B2 (cluster B) isolates were shown to be completely different (PTII and PTXVIII), even though

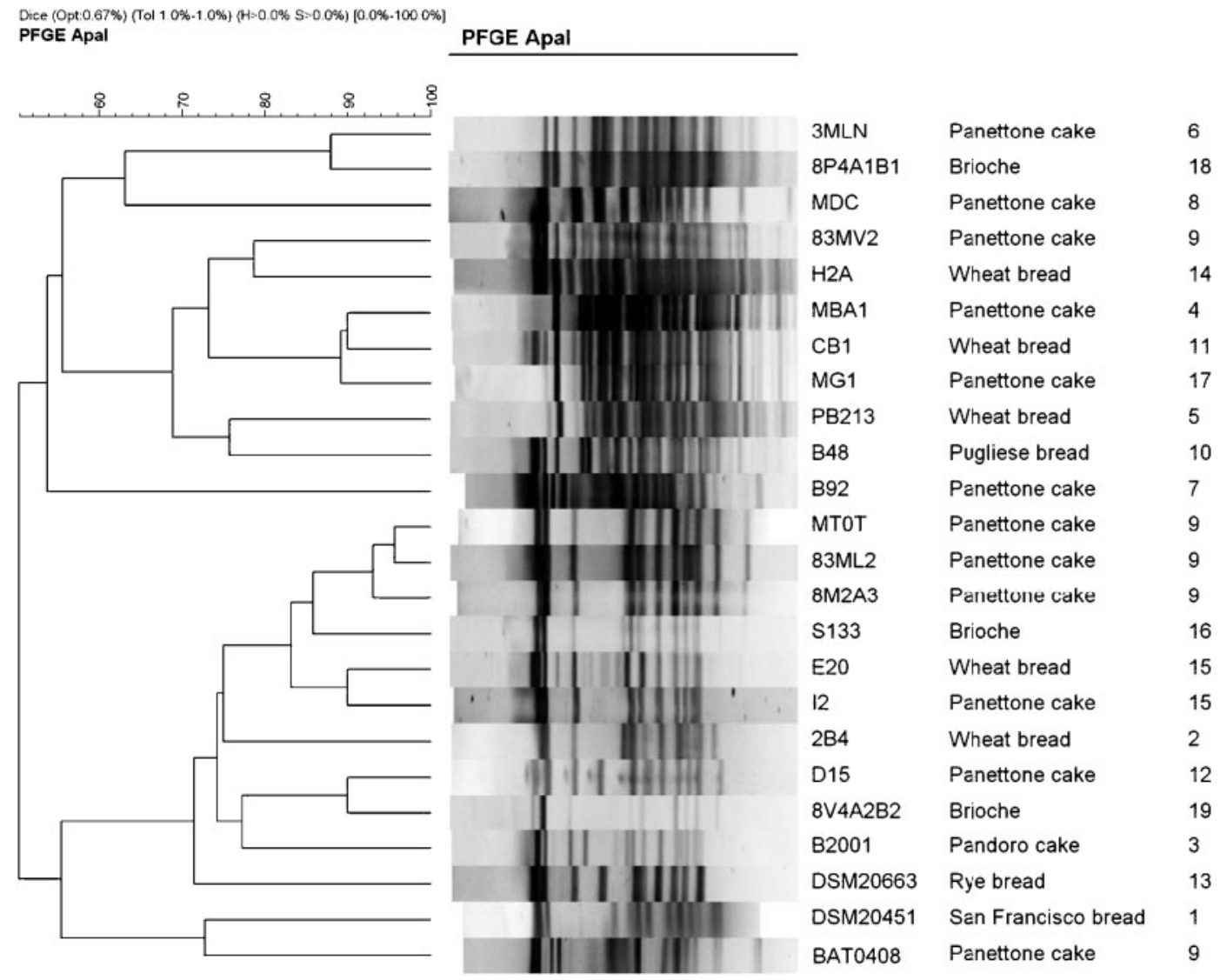

Fig. 1. PFGE analysis of $L$. sanfranciscensis strains after digestion with Apal. The dendrogram was constructed by UPGMA cluster analysis of the restriction profiles. The scale bar shows percentage similarity. 
these micro-organisms were isolated from sourdough samples originated from the same 'mother', which was back-slopped in two different sites, Perugia and Verona, of the same firm (B).

\section{Diversity in housekeeping genes}

Since the genome sequence of $L$. sanfranciscensis had not been completed when this study was performed, a number of candidate loci were identified by searching the $L$. sanfranciscensis gene sequences deposited (http://ncbi.nlm. nih.gov). These genes can be differentiated into two functionally distinct classes: informational $(g y r A)$, which are involved in information processing; and operational ( $g d h, m a p A, p g m A$, pta and nox), which function in day-to-day processes of cell maintenance (Rivera et al., 1998).

The six genes were successfully amplified for all $24 \mathrm{~L}$. sanfranciscensis strains, and sequenced in forward and reverse direction to confirm the order of the nucleotides. Fig. 2 shows the position of the polymorphic sites for each locus, indicating the changed nucleotides with respect to the consensus sequence reported in GenBank for the DSM20451 ${ }^{\mathrm{T}}$ strain. For all loci the 24 sequences aligned without gaps or insertions. All loci were polymorphic, and

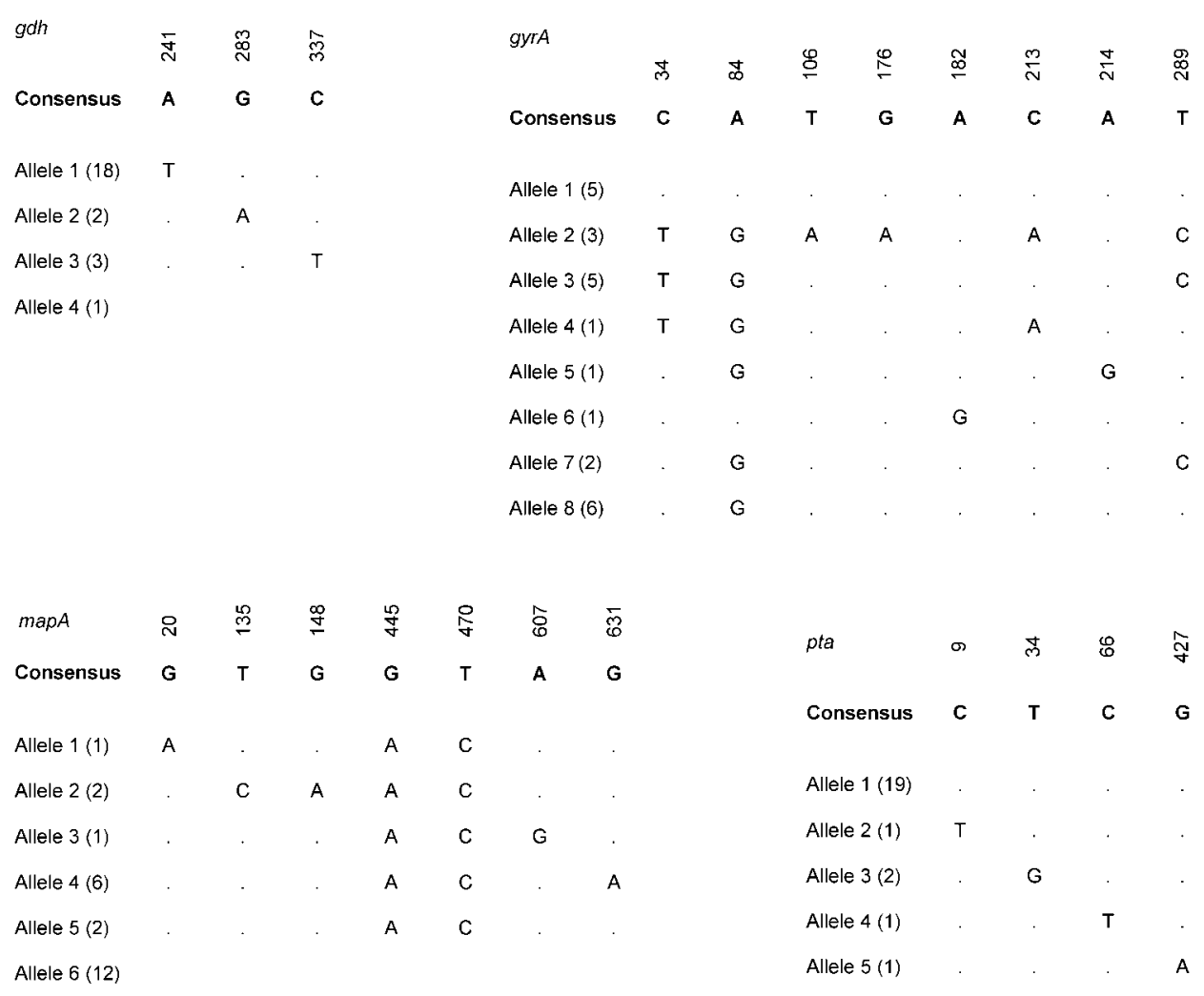

\begin{tabular}{|c|c|c|c|c|c|c|c|c|c|}
\hline nox & $\underset{\tau}{\tau}$ & $\stackrel{2}{\circ}$ & $\stackrel{m}{\leftarrow}$ & 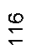 & $\stackrel{\infty}{\infty}$ & $\bar{g}$ & $\begin{array}{l}\text { पे } \\
\stackrel{\alpha}{\alpha}\end{array}$ & 喽 & $\rho g m A$ \\
\hline Consensus & c & c & c & G & A & G & c & A & Consensus \\
\hline Allele 1 (1) & . & & & & & & & & Allele 1 (19) \\
\hline Allele $2(5)$ & . & . & & A & . & & $\cdot$ & & Allele $2(5)$ \\
\hline Allele $3(1)$ & $T$ & & & A & & & & & \\
\hline Allele 4 (1) & . & T & T & A & . & & . & & \\
\hline Allele 5 (3) & . & & & A & G & & A & & \\
\hline Allele $6(10)$ & . & . & 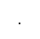 & A & - & $T$ & . & & \\
\hline Allele 7 (2) & & & . & A & & & A & & \\
\hline Allele 8 (1) & & & & A & & & & G & \\
\hline
\end{tabular}

Fig. 2. Polymorphic nucleotide sites in L. sanfranciscensis MLST genes. Only the variable sites are shown. The number of strains possessing an allele is indicated in parentheses. 
the number of polymorphic nucleotide sites varied between one in pgmA and eight in gyrA and nox, suggesting a different evolution rate. Fragments with a length between 353 (pgmA) and $648 \mathrm{bp}($ nox) allowed the identification of the number of alleles per locus as between two (pgmA) and eight (gyrA and nox) (Table 3). The observed frequencies showed that one allele was dominant for most of the loci (mapA, gdh, pta and pgmA) (Table 1). The mean G+C content of the different gene fragments varied from 34.79 (nox) to 47.64 and $48.38 \mathrm{~mol} \%$ (mapA and pgmA, respectively). By combining the sequence results of the six loci, 19 STs were distinguished. The UPGMA dendrogram in Fig. 3 shows the genetic relatedness among the $L$. sanfranciscensis strains investigated. In most cases, the identified ST profiles allowed the strains to be distinguished by a unique combination of alleles, though with limited variation. In fact, ST3 (B2001) diverged from ST15 (E20 and I2) only at the gyrA locus, and ST16 (S133) and ST18 (8P4A1B1) differed only at the mapA locus. Furthermore, the ST18 profile diverged from ST19 (8V4A2B2) only at the gdh locus, and ST15, ST17 (MG1) and ST18 can be distinguished only by a polymorphism in nox. With respect to the sequence reported in GenBank for the DSM20451 ${ }^{\mathrm{T}}$ nox gene, a thymine instead of a cytosine is present at position 32 .

No significant clusters that correlated with geographical origin, type of sourdough or year of isolation were observed. However, ST9 grouped five isolates, four of which were collected from sourdoughs from firm A in different years, and one of which was from firm $Q$.

The values of $d_{N}$ (number of non-synonymous changes per non-synonymous site) and of $d_{S}$ (number of synonymous changes per synonymous site) were calculated for each gene. The $\mathrm{d}_{\mathrm{N}} / \mathrm{d}_{\mathrm{S}}$ ratios were evaluated and, for all loci but two (gyrA and mapA), were $<1$ (Table 3), indicating that a high selective pressure against amino acid changes was present.

In-frame concatenated gene sequence fragments from all the loci were analysed and drawn in a graphic using SPLITSTREE software (Fig. 4a); the tree-like structure that was obtained suggested a clonal descent. The split decomposition analysis, afterwards calculated for the alleles of each locus, matched the clonal nature of the evolution in the tested genes, since tree-like structures were observed. Only the graph for gyrA presented a parallelogram-like structure, suggestive of intragenic recombination (Fig. 4b). The split graph for pgmA showed a line, since only two alleles were examined. When the sum of squares of condensed fragments was considered, Sawyer's test revealed no evident occurrence of intragenic recombination in the samples (Table 4). This result was supported by the values obtained with the maximum condensed fragment method $(P=1.000)$. The linkage disequilibrium among alleles was estimated from the $\mathrm{I}_{\mathrm{A}}$ value. Since this index showed a value of 0.4344 , significantly higher than 0 , a clonal population could be identified. Furthermore, the standardized $\mathrm{I}_{\mathrm{A}}$ value $\left(\mathrm{I}_{\mathrm{A}}^{\mathrm{S}}\right)$, which is independent of the number of loci, was 0.0869 , indicative of a limited recombination among genes.

\section{Comparative results for PFGE versus MLST}

The discriminatory power of the two typing analyses was compared: PFGE differentiated 22 pulsotypes, whereas the MLST protocol recognized 19 STs. Some strains that proved to be indistinguishable by PFGE analysis, such as isolates 8M2A3, MT0T and 83ML2 (PTXII), revealed identical sequences for all the gene fragments that were analysed (ST9). On the other hand, isolates 83MV2 and BAT0408, belonging to the same ST (ST9), were located in different PFGE clusters (A and B) and were not related to PTXII.

For each of the other strains (except E20 and I2, see below), a single pulsotype and ST were determined. In fact, strains showing very similar restriction profiles, such as MBA1 and CB1 or D15 and 8V4A2B2, presented distant allelic STs (ST4 and ST11 or ST12 and ST19, respectively).

An interesting outcome, validated through results from both PFGE and MLST analyses, was the inconsistency of the geographical factor in the evolution of the dominant bacterial populations naturally selected in sourdough fermentations. In fact, strains isolated in the same town (Verona) but from six different firms (A, B, F, L, M and P) showed dissimilar pulsotypes and distinct STs. On the other hand, strains E20 and I2, which exhibited a unique ST profile (ST15) and closely related PFGE patterns, were isolated in two different Italian regions.

Table 3. Descriptive analysis of MLST data

\begin{tabular}{|c|c|c|c|c|c|}
\hline Gene & Fragment analysed (bp) & Mean G $+\mathrm{C}$ content $(\mathrm{mol} \%)$ & Polymorphic sites ${ }^{\star}$ & Alleles & $\mathbf{d}_{\mathrm{N}} / \mathbf{d}_{\mathrm{s}}$ \\
\hline gyrA & 357 & 37.87 & $8(2)$ & 8 & 1.1522 \\
\hline mapA & 632 & 47.64 & $7(1)$ & 6 & 1.5710 \\
\hline$g d h$ & 396 & 36.07 & $3(0)$ & 4 & - \\
\hline pta & 459 & 40.08 & $4(2)$ & 5 & 0.2997 \\
\hline nox & 648 & 34.79 & $8(3)$ & 8 & 0.5504 \\
\hline $\operatorname{pgmA}$ & 353 & 48.38 & $1(1)$ & 2 & 0.0000 \\
\hline
\end{tabular}

${ }^{\star}$ Number of silent polymorphic sites in parentheses. 


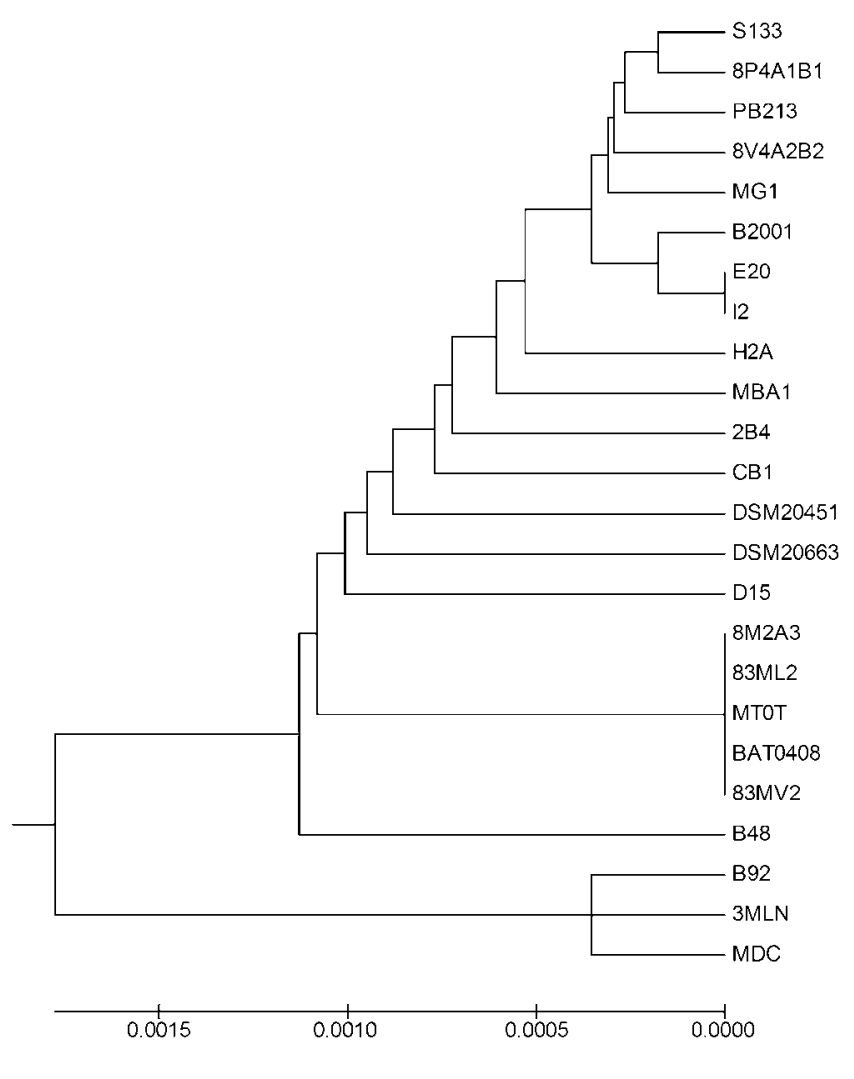

Fig. 3. UPGMA tree generated from allelic profiles showing the genetic relatedness of the $L$. sanfranciscensis strains examined in this study. The scale bar indicates genetic relatedness.

\section{Generation time of an $L$. sanfranciscensis strain under industrial conditions}

Samples were aseptically collected every $2 \mathrm{~h}$ during the whole ripening time of the 'mother' $(16 \mathrm{~h})$ and immediately analysed at the laboratory of firm A. Through the elaboration of results obtained from plate counts the generation time was calculated to be $4 \mathrm{~h}$. A few colonies at the highest dilutions were randomly picked at each monitoring time. Species identification was carried out by the analysis of the internal ribosomal spacers, as described by Valcheva et al. (2007).

\section{DISCUSSION}

L. sanfranciscensis is considered the dominant bacterial species in sourdough technology, and requires a daily propagation of the so-called 'mother' dough (type I process) (De Vuyst et al., 2009; Foschino et al., 2001; Gobbetti et al., 1996; Vogel et al., 1999). Nevertheless, the use of this micro-organism in starter cultures for bakery has not yet been fully exploited, and its presence in the form of viable selected strains has never been successfully applied in starter programme management.

The use of PFGE analysis has proved to be helpful in discriminating $L$. sanfranciscensis isolates collected from different fermentation processes (Zapparoli et al., 1998). However, the need for dedicated tools and skilled staff, presence of strains that do not generate restriction profiles, and the possibility of recombination events within the same strain make the application of PFGE as a routine technique difficult. A suitable typing protocol that can allow a precise identification and that can be easily used in an inter-laboratory data comparison is necessary. MLST, a method that is based on partial nucleotide sequences of multiple housekeeping genes, has recently been shown to be a powerful technique for bacterial typing in food fermentations (De las Rivas et al., 2006; Tanganurat et al., 2009). Housekeeping genes are preferred, because an analysis of mutations in such genes is more likely to properly reflect the phylogeny of strains, since such genes evolve slowly and therefore can indicate the genetic relationships among bacterial isolates more accurately than genes under selective pressure. MLST uses variation that accumulates slowly, which is expected to be selectively neutral, and achieves very high resolution by analysing multiple loci.

Thus, we characterized a collection of $24 \mathrm{~L}$. sanfranciscensis strains through MLST and compared the results with those of PFGE analysis. The high discriminatory power of PFGE was confirmed, since we identified 22 pulsotypes and detected two major clusters (A and B). Even though we sequenced six genes, we were not able to obtain the same discrimination level with MLST analysis. This lack of discrimination has been reported in other studies (Cai et al., 2007; Johnson et al., 2007), and is probably due to the fact that, since PFGE is based on restriction patterns, every single point mutation in the few enzyme recognition sites throughout the genome could significantly alter the profile. Moreover, this could explain why the cluster analysis obtained with the two techniques generates different and not similar results, considering that the evolution rate of housekeeping genes is different from the rearrangement rate of the whole genome. Notably, micro-organisms that cluster together in a single pulsotype (PTXII) were collected from the same firm (A) in three consecutive years. We assumed that these three isolates (8M2A3, 83ML2 and MT0T) belonged to the same strain and that, therefore, a single bacterial population might be predominant, at least for 32 months, in a 'mother' dough refreshed every day under standardized and controlled conditions of temperature, redox potential, moisture, recipe formulation and time of ripening (Picozzi et al., 2009). Furthermore, this evidence was strengthened by the results of MLST, which revealed the same ST (ST9) for the three isolates considered above. Taking into account that the generation time for $L$. sanfranciscensis was calculated as approximately $4 \mathrm{~h}$, under the operating conditions at the plant, we estimated that both the genome structure and the nucleotide sequences of the examined loci were unchanged for approximately 5900 cellular duplications. On the other hand, the evidence that when a 'mother' dough is transferred from one firm to another the dominant population changes is proof that environmental conditions and industrial practices strongly 


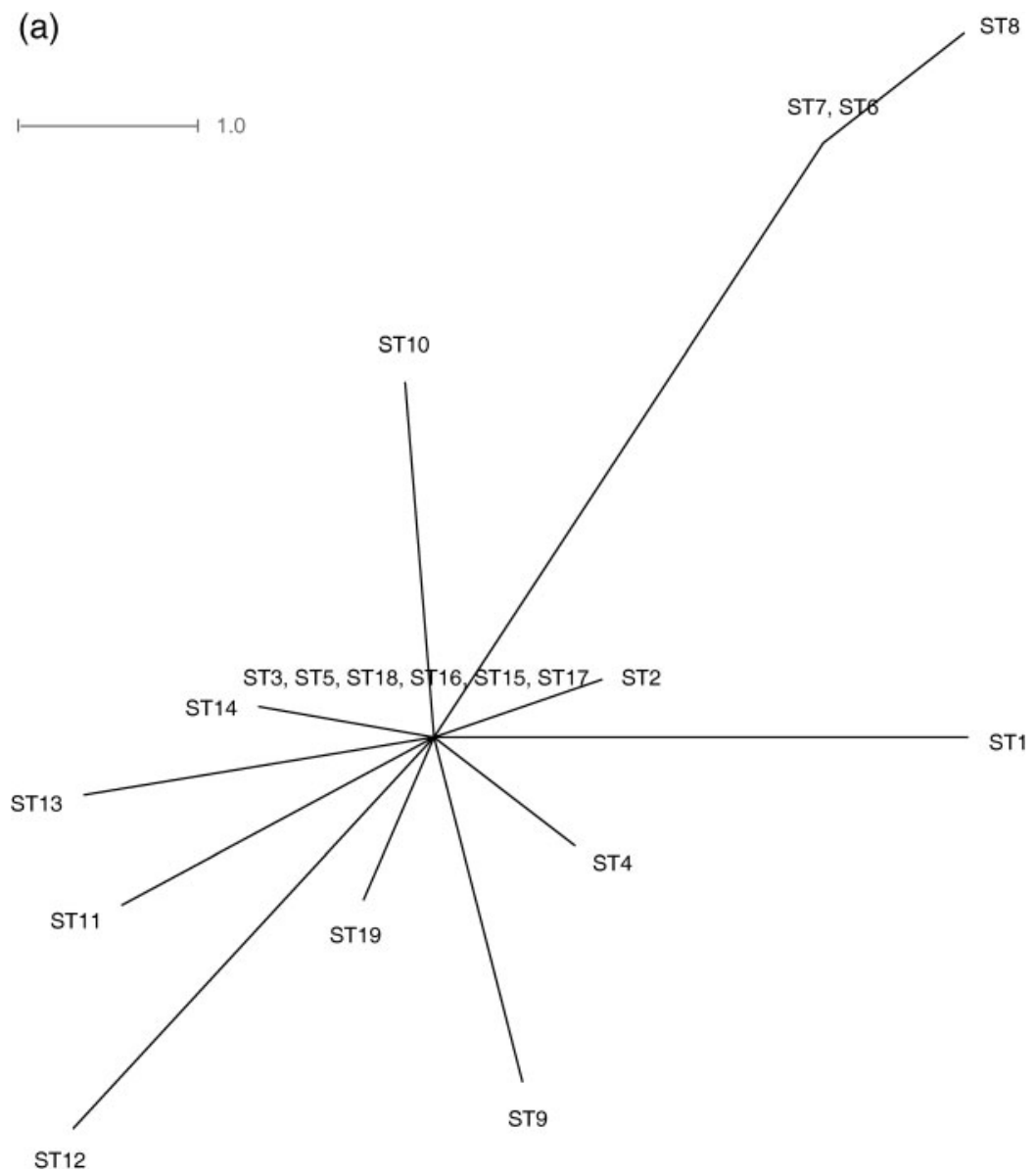

Fig. 4. (a) Split decomposition analysis based on concatenated sequences of six housekeeping genes. The numbering refers to the ST profile. (b) Split decomposition analysis of alleles obtained for six loci. The parallelogram structures are suggestive of recombination. All branch lengths are drawn to scale. The numbering refers to allele numbers. The bars indicate the scale for the branch lengths.

affect the structure of the bacterial communities in a type I sourdough process. In fact, the original strain recovered from the 'mother' dough for brioche production sampled in Perugia was no longer found as the dominant strain in the 'mother' dough after 4 months of back-slopping in Verona.

Our findings support the thesis of De Vuyst et al. (2009) and Scheirlinck et al. (2009) on the evolution of lactobacilli populations in a type I sourdough: they suggest that the processing conditions and the manufacturing environment, rather than the geographical area, are the factors mainly influencing the dominance of a strain.

As regards MLST analysis, the six investigated loci proved to be polymorphic. The sequencing of the pgmA fragment displayed only two alleles; the removal of this gene from the analysis led to the same number of STs. Furthermore, $\operatorname{pgmA}$ is adjacent to mapA on the chromosome of DSM20451, and may therefore be horizontally transferred by a single recombination event, introducing inaccuracies in evolution rate estimations. Nevertheless, we kept the $\operatorname{pgmA}$ gene in this work because of the differences shown by allele 2, which remarkably are present in only five isolates (Table 1), confirming the high similarity among them. Notably, strains 83ML2 and 83MV2, which were isolated on the same day from samples from two different plants of the same firm (A), showed different PFGE profiles. This observation led to the hypothesis that a recombination event could have taken place at a previous time when the mother dough had been transferred from Milan to Verona. An optimization of the MLST scheme with another housekeeping gene with a higher number of alleles is suggested. Almost all the STs that were identified are represented by a single strain; the only two exceptions correspond to ST9 and ST15 (five and two isolates, respectively). The results obtained by split decomposition analysis of the six loci suggest a low rate of mutation and thus the occurrence of a rare recombination in these housekeeping genes. The same result could be obtained if we look at the lack of mosaic structure in the aligned sequences (Fig. 2). Our results differ from those obtained for similar species used in food fermentations, such as $O$. oeni, L. casei and L. plantarum, for which evidence of 

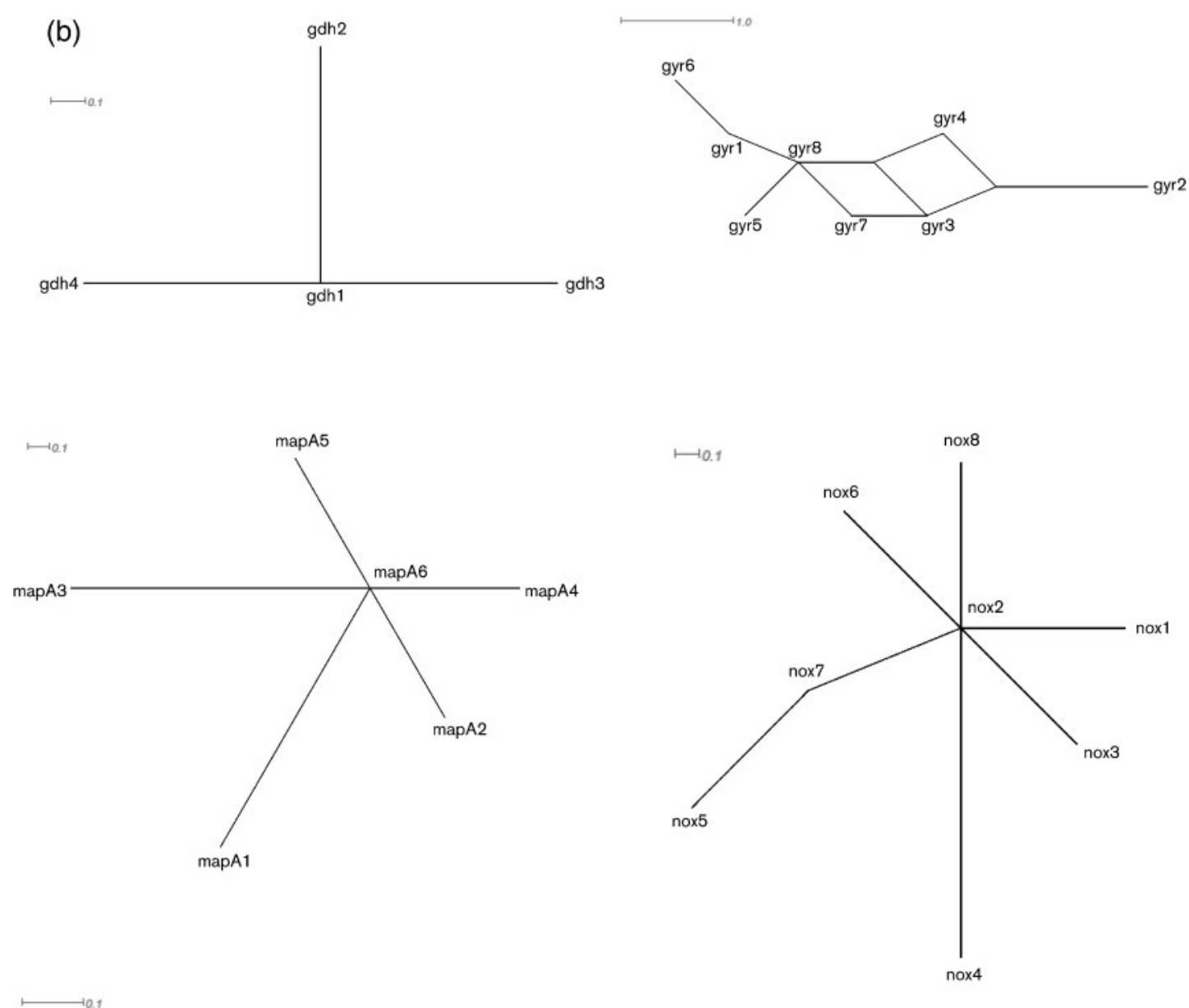

pgmA1

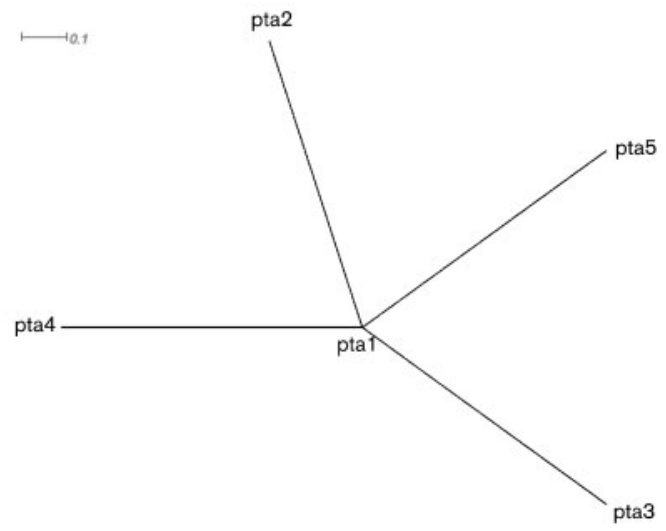

panmitic populations has been demonstrated (De las Rivas et al., 2006; Cai et al., 2007; Bilhère et al., 2009). The clonality of $L$. sanfranciscensis strains observed in this work could be explained by the emergence of a recent common ancestor, revealing the ability of this species to dominate the microbial consortia in sourdough production under harsh environmental conditions. The overall $\mathrm{G}+\mathrm{C}$ content of $34.71 \mathrm{~mol} \%$ estimated for the $L$. sanfranciscensis chromosome (Vogel et al., 2009) is not a definitive value, since when we were writing this work, the whole genome sequence of this species had not been published. Therefore, the differences between this value and those obtained from the housekeeping genes examined cannot be ascribed with confidence to a recent acquisition. Nevertheless, the pgmA and mapA allele sequences showed an unexpectedly high $\mathrm{G}+\mathrm{C}$ content, confirming the stability of the amino acid sequences of these two enzymes and the significance of their catabolic abilities for survival in a sourdough environment. In fact, these two genes encode enzymes involved in the metabolism and transport of maltose into 
Table 4. Sawyer's test analysis for evidence of intragenic recombination

\begin{tabular}{|lrl|}
\hline Locus & SSCF $^{*}(\boldsymbol{P})$ & $\mathbf{M C F} \dagger(P)$ \\
\hline$g y r$ & $72(1.000)$ & $2(1.000)$ \\
mapA & $10(1.000)$ & $1(1.000)$ \\
$g d h$ & $0(1.000)$ & $0(1.000)$ \\
pta & $18(1.000)$ & $2(1.000)$ \\
nox & $143(1.000)$ & $3(1.000)$ \\
pgmA & $0(1.000)$ & $0(1.000)$ \\
\hline
\end{tabular}

${ }^{\star}$ Sum of squares of condensed fragments.

$\dagger$ Maximum condensed fragment.

the cell; therefore, they are critical to the dominance of this species in sourdough, where maltose is the most available sugar. In fact, sourdough is the only habitat known to date where L. sanfranciscensis prevails, on account of its specialized metabolism and its high resistance to an acid environment. The high $\mathrm{G}+\mathrm{C}$ content in mapA seems to be in disagreement with the results in Table 3 , where it is shown that of seven polymorphic sites in this gene, only one silent site was found. This could be explained by considering that the sequenced fragment for this locus is positioned in a region located between the two catalytic sites of the enzyme. Thus, the non-silent changes do not affect the activity of the MapA protein. In the same way, gyrA shows an elevated number of non-silent polymorphic sites. This is an even more unexpected result, since this is an informational gene and for this reason is considered less malleable from an evolutionary point of view (Rivera et al., 1998). Since there is no available information on the tertiary structure of the catalytic site for this species, we can only theorize that the mutations observed in almost $50 \%$ of our strains do not lead to a conformational change of the protein and therefore to a loss of its activity.

In conclusion, the MLST scheme that we developed in this work could be useful for a precise discrimination at the strain level for this species. Considering industrial applications, this technique might appear quite expensive, but it could be a suitable tool for safeguarding brands or the Protected Designation of Origin of typical products.

\section{ACKNOWLEDGEMENTS}

The authors gratefully thank the personnel of the firms involved in this work for their precious collaboration. We thank Professor A. Corsetti (Università degli Studi di Teramo, Italy), Professor M. Gobbetti ((Università di Bari, Italy), Dr C. Randazzo (Università di Catania, Italy) and Dr G. Zapparoli (Università di Verona, Italy) for providing some of the $L$. sanfranciscensis strains.

\section{REFERENCES}

Arendt, E. K., Ryan, L. A. M. \& Dal Bello, F. (2007). Impact of sourdough on the texture of bread. Food Microbiol 24, 165-174.
Bilhère, E., Lucas, P. M., Claisse, O. \& Lonvaud-Funel, A. (2009). Multilocus sequence typing of Oenococcus oeni: detection of two subpopulations shaped by intergenic recombination. Appl Environ Microbiol 75, 1291-1300.

Borgo, F., Ricci, G., Manachini, P. L. \& Fortina, M. G. (2007). Multilocus restriction typing: a tool for studying molecular diversity within Lactobacillus helveticus of dairy origin. Int Dairy J 17, 336-342.

Cai, H., Rodriguez, B. T., Zhang, W., Broadbent, J. R. \& Steele, J. L. (2007). Genotypic and phenotypic characterization of Lactobacillus casei strains isolated from different ecological niches suggests frequent recombination and niche specificity. Microbiology 153, 2655-2665.

Catzeddu, P., Mura, E., Parente, E., Sanna, M. \& Farris, G. A. (2006). Molecular characterization of lactic acid bacteria from sourdough breads produced in Sardinia (Italy) and multivariate statistical analyses of results. Syst Appl Microbiol 29, 138-144.

Corsetti, A., Gobbetti, M., Balestrieri, F., Paoletti, F., Russi, L. \& Rossi, J. (1998a). Sourdough lactic acid bacteria effects on bread firmness and staling. J Food Sci 63, 347-351.

Corsetti, A., Gobbetti, M., Rossi, J. \& Damiani, P. (1998b). Antimould activity of sourdough lactic acid bacteria: identification of a mixture of organic acids produced by Lactobacillus sanfrancisco CB1. Appl Microbiol Biotechnol 50, 253-256.

Corsetti, A., Gobbetti, M., De Marco, B., Balestrieri, F., Paoletti, F., Russi, L. \& Rossi, J. (2000). Combined effects of sourdough lactic acid bacteria on bread firmness and staling. J Agric Food Chem 48, 3044-3051.

Corsetti, A., Lavermicocca, P., Morea, M., Baruzzi, F., Tosti, N. \& Gobbetti, M. (2001). Phenotypic and molecular characterization and clustering of lactic acid bacteria and yeasts from wheat (species Triticum durum and Triticum aestivum) sourdoughs of southern Italy. Int J Food Microbiol 64, 95-104.

Corsetti, A., Settanni, L., Valmorri, S., Mastrangelo, M. \& Suzzi, G. (2007). Identification of subdominant sourdough lactic acid bacteria and their evolution during laboratory-scale fermentations. Food Microbiol 24, 592-600.

De Angelis, M., Di Cagno, R., Gallo, G., Curci, M., Siragusa, S., Crecchio, C., Parente, E. \& Gobbetti, M. (2007). Molecular and functional characterization of Lactobacillus sanfranciscensis strains isolated from sourdough. Int J Food Microbiol 114, 69-82.

De las Rivas, B., Marcobal, A. \& Muñoz, R. (2004). Allelic diversity and population structure in Oenococcus oeni as determined from sequence analysis of housekeeping genes. Appl Environ Microbiol 70, $7210-7219$.

De las Rivas, B., Marcobal, A. \& Muñoz, R. (2006). Development of a multilocus sequence typing method for analysis of Lactobacillus plantarum strains. Microbiology 152, 85-93.

De Vuyst, L. \& Neysens, P. (2005). The sourdough microflora: biodiversity and metabolic interactions. Trends Food Sci Technol 16, 43-56.

De Vuyst, L., Vrancken, G., Ravyts, F., Rimaux, T. \& Weckx, S. (2009). Biodiversity, ecological determinants, and metabolic exploitation of sourdough microbiota. Food Microbiol 26, 666-675.

Diancourt, L., Passet, V., Chervaux, C., Garault, P., Smokvina, T. \& Brisse, S. (2007). Multilocus sequence typing of Lactobacillus casei reveals a clonal population structure with low levels of homologous recombination. Appl Environ Microbiol 73, 6601-6611.

Di Cagno, R., De Angelis, M., Lavermicocca, P., De Vincenzi, M., Giovannini, C. \& Gobbetti, M. (2002). Proteolysis by sourdough lactic acid bacteria: effects on wheat flour protein fractions and gliadin peptides involved in human cereal intolerance. Appl Environ Microbiol 68, 623-633.

Di Cagno, R., De Angelis, M., Auricchio, S., Greco, L., Clarke, C., De Vincenzi, M., Giovannini, C., D’Archivio, M., Landolfo, F. \& other 
authors (2004). Sourdough bread made from wheat and nontoxic flours and started with selected lactobacilli is tolerated in celiac sprue patients. Appl Environ Microbiol 70, 1088-1096.

Di Cagno, R., De Angelis, M., Alfonsi, G., De Vincenzi, M., Silano, M., Vincentini, O. \& Gobbetti, M. (2005). Pasta made from durum wheat semolina fermented with selected lactobacilli as a tool for a potential decrease of the gluten intolerance. J Agric Food Chem 53, 4393-4402.

Foschino, R., Arrigoni, C., Picozzi, C., Mora, D. \& Galli, A. (2001). Phenotypic and genotypic aspects of Lactobacillus sanfranciscensis isolated from sourdoughs in Italy. Food Microbiol 18, 277-285.

Gobbetti, M., Corsetti, A. \& Rossi, J. (1996). Lactobacillus sanfrancisco, a key sourdough lactic acid bacterium: physiology, genetic and biotechnology. Adv Food Sci 18, 167-175.

Gobbetti, M., Rizzello, C. G., Di Cagno, R. \& De Angelis, M. (2007). Sourdough lactobacilli and celiac disease. Food Microbiol 24, 187-196.

Hansen, A. \& Schieberle, P. (2005). Generation of aroma compounds during sourdough fermentation: applied and fundamental aspects. Trends Food Sci Technol 16, 85-94.

Haubold, B. \& Hudson, R. R. (2000). LIAN 3.0: detecting linkage disequilibrium in multilocus data. Linkage analysis. Bioinformatics 16, 847-848.

Huson, D. H. \& Bryant, D. (2006). Application of phylogenetic networks in evolutionary studies. Mol Biol Evol 23, 254-267.

Johnson, J. K., Arduino, S. M., Colin Stine, O., Johnson, J. \& Harris, A. D. (2007). Multilocus sequence typing compared to pulsed-field gel electrophoresis for molecular typing of Pseudomonas aeruginosa. J Clin Microbiol 45, 3707-3712.

Korakli, M., Rossmann, A., Ganzle, M. G. \& Vogel, R. F. (2001). Sucrose metabolism and exopolysaccharide production in wheat and rye sourdoughs by Lactobacillus sanfranciscensis. J Agric Food Chem 49, 5194-5200.

Korakli, M., Pavlovic, M., Ganzle, M. G. \& Vogel, R. F. (2003). Exopolysaccharide and kestose production by Lactobacillus sanfranciscensis LTH2590. Appl Environ Microbiol 69, 2073-2079.

Kumar, S., Tamura, K. \& Nei, M. (1994). MEGA: Molecular Evolutionary Genetics Analysis software for microcomputers. Comput Appl Biosci 10, 189-191.

Lacaze, G., Wick, M. \& Cappelle, S. (2007). Emerging fermentation technologies: development of novel sourdough. Food Microbiol 24, 155-160.

Liljeberg, H. G. M. \& Björck, I. M. E. (1996). Delayed gastric emptying rate as a potential mechanism for lowered glycemia after eating sourdough bread: studies in humans and rats using test products with added organic acids or an organic salt. Am J Clin Nutr 64, 886-893.

Liljeberg, H. G. M., Lönner, C. H. \& Björck, I. M. E. (1995). Sourdough fermentation or addition of organic acids or corresponding salts to bread improves nutritional properties of starch in healthy humans. J Nutr 125, 1503-1511.

Meroth, C. B., Walter, J., Hertel, C., Brandt, M. J. \& Hammes, W. P. (2003). Monitoring the bacterial population dynamics in sourdough fermentation processes by using PCR-denaturing gradient gel electrophoresis. Appl Environ Microbiol 69, 475-482.

Moore, M. M., Juga, B., Schober, T. J. \& Arendt, E. K. (2007). Effect of lactic acid bacteria on properties of gluten-free sourdoughs, batters, and quality and ultrastructure of gluten-free bread. Cereal Chem 84, 357-364.

Nei, M. \& Gojobori, T. (1986). Simple methods for estimating the numbers of synonymous and nonsynonymous nucleotide substitutions. Mol Biol Evol 3, 418-426.

Picozzi, C., Gallina, S., Della Fera, T. \& Foschino, R. (2005). Comparison of cultural media for the enumeration of sourdough lactic acid bacteria. Ann Microbiol 55, 319-320.
Picozzi, C., D'Anchise, F. \& Foschino, R. (2006). PCR detection of Lactobacillus sanfranciscensis in sourdough and panettone baked product. Eur Food Res Technol 222, 330-335.

Picozzi, C., Vigentini, I. \& Foschino, R. (2009). How long does the same strain of Lactobacillus sanfranciscensis inhabit a panettone sourdough? In 4th International Symposium on Sourdough - from Arts to Science, 14-17 October 2009, Freising, Germany, p. 28.

Randazzo, C. L., Heilig, H., Restuccia, C., Giudici, P. \& Caggia, C. (2005). Bacterial population in traditional sourdough evaluated by molecular methods. J Appl Microbiol 99, 251-258.

Ravelo, C., Magarinos, B., Lopez-Romalde, S., Toranzo, A. E. \& Romalde, J. (2003). Molecular fingerprinting of fish-pathogenic Lactococcus garvieae strains by random amplified polymorphic DNA analysis. J Clin Microbiol 41, 751-756.

Rivera, M. C., Jain, R., Moore, J. E. \& Lake, J. A. (1998). Genomic evidence for two functionally distinct gene classes. Proc Natl Acad Sci U S A 95, 6239-6244.

Scheirlinck, I., Van der Meulen, R., De Vuyst, L., Vandamme, P. \& Huys, G. (2009). Molecular source tracking of predominant lactic acid bacteria in traditional Belgian sourdoughs and their production environments. J Appl Microbiol 106, 1081-1092.

Schnürer, J. \& Magnusson, J. (2005). Antifungal lactic acid bacteria as biopreservatives. Trends Food Sci Technol 16, 70-78.

Smith, J. M., Smith, N. H., O'Rourke, M. \& Spratt, B. G. (1993). How clonal are bacteria? Proc Natl Acad Sci U S A 90, 4384-4388.

Tanganurat, W., Quinquis, B., Leelawatcharamas, V. \& Bolotin, A. (2009). Genotypic and phenotypic characterization of Lactobacillus plantarum strains isolated from Thai fermented fruits and vegetables. J Basic Microbiol 49, 377-385.

Tenover, F. C., Arbeit, R. D., Goering, R. V., Mickelsen, P. A., Murray, B. E., Persing, D. H. \& Swaminathan, B. (1995). Interpreting chromosomal DNA restriction patterns produced by pulsed-field gel electrophoresis: criteria for bacterial strain typing. J Clin Microbiol 33, 2233-2239.

Thiele, C., Ganzle, M. G. \& Vogel, R. F. (2002). Contribution of sourdough lactobacilli, yeast, and cereal enzymes to the generation of amino acids in dough relevant for bread flavour. Cereal Chem 79, 4551.

Tieking, M. \& Gänzle, M. G. (2005). Exopolysaccharides from cerealassociated lactobacilli. Trends Food Sci Technol 16, 79-84.

Valcheva, R., Kabadjova, P., Racman, C., Ivanova, I., Onno, B., Prévost, H. \& Dousset, X. (2007). A rapid PCR procedure for the specific identification of Lactobacillus sanfranciscensis, based on the 16S-23S intergenic spacer regions. J Appl Microbiol 102, 290-302.

Vogel, R. F., Muller, M., Stoltz, P. \& Ehrmann, M. (1996). Ecology in sourdoughs produced by traditional and modern technology. $A d v$ Food Sci 18, 152-159.

Vogel, R. F., Knorr, R., Muller, M. R. A., Steudel, U., Ganzle, M. G. \& Ehrmann, M. A. (1999). Non-dairy lactic fermentation: the cereal world. Antonie Van Leeuwenhoek 76, 403-411.

Vogel, R. F., Liebl, W., Rattei, T., Pavlovic, M. \& Ehrmann, M. (2009). Lactobacillus sanfranciscensis - insights from the genome. In $4 t h$ International Symposium on Sourdough - from Arts to Science, 1417 October 2009, Freising, Germany, p. 21.

Zapparoli, G., Torriani, S. \& Dellaglio, F. (1998). Differentiation of Lactobacillus sanfranciscensis strains by randomly amplified polymorphic DNA and pulsed-field gel electrophoresis. FEMS Microbiol Lett 166, 325-332.

Edited by: P. W. O'Toole 